\title{
Removal of organic contaminants in bioretention medium amended with activated carbon from sewage sludge
}

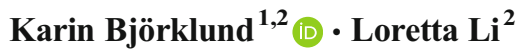

Received: 25 January 2017 / Accepted: 9 June 2017 / Published online: 29 June 2017

(C) The Author(s) 2017. This article is an open access publication

\begin{abstract}
Bioretention, also known as rain garden, allows stormwater to soak into the ground through a soil-based medium, leading to removal of particulate and dissolved pollutants and reduced peak flows. Although soil organic matter (SOM) is efficient at sorbing many pollutants, amending the bioretention medium with highly effective adsorbents has been proposed to optimize pollutant removal and extend bioretention lifetime. The aim of this research was to investigate whether soil amended with activated carbon produced from sewage sludge increases the efficiency to remove hydrophobic organic compounds frequently detected in stormwater, compared to nonamended soil. Three lab-scale columns $\left(520 \mathrm{~cm}^{3}\right)$ were packed with soil (bulk density $\left.1.22 \mathrm{~g} / \mathrm{cm}^{3}\right)$; activated carbon $(0.5 \% \mathrm{w} /$ w) was added to two of the columns. During 28 days, synthetic stormwater - ultrapure water spiked with seven hydrophobic organic pollutants and dissolved organic matter in the form of humic acids - was passed through the column beds using upward flow $(45 \mathrm{~mm} / \mathrm{h})$. Pollutant concentrations in effluent water (collected every $12 \mathrm{~h}$ ) and polluted soils, as well as desorbed amounts of pollutants from soils were determined using GC-
\end{abstract}

Responsible editor: Philippe Garrigues

Electronic supplementary material The online version of this article (doi:10.1007/s11356-017-9508-1) contains supplementary material, which is available to authorized users.

Karin Björklund

karin.bjorklund@chalmers.se

1 Department of Civil and Environmental Engineering, Chalmers University of Technology, Sven Hultins Gata 8, SE-41296 Goteborg, Sweden

2 Department of Civil Engineering, University of British Columbia, 6250 Applied Science Lane, Vancouver, BC V6T 1Z4, Canada
MS. Compared to SOM, the activated carbon exhibited a significantly higher adsorption capacity for tested pollutants. The amended soil was most efficient for removing moderately hydrophobic compounds ( $\left.\log K_{\text {ow }} 4.0-4.4\right)$ : as little as $0.5 \%$ ( $w /$ $w$ ), carbon addition may extend bioretention medium lifetime by approximately 10-20 years before saturation of these pollutants occurs. The column tests also indicated that released SOM sorb onto activated carbon, which may lead to early saturation of sorption sites on the carbon surface. The desorption test revealed that the pollutants are generally strongly sorbed to the soil particles, indicating low bioavailability and limited biodegradation.

Keywords Bioretention · Column test · Dissolved organic matter · Hydrophobic organic pollutants · Rain garden · Sorption $\cdot$ Soil amendment $\cdot$ Stormwater management

\begin{tabular}{ll}
\multicolumn{2}{l}{ Acronyms } \\
ANT & Anthracene \\
DBP & Dibutyl phthalate \\
DEHP & Di(2-ethylhexyl) phthalate \\
DOC & Dissolved organic carbon \\
DOM & Dissolved organic matter \\
FL & Fluorene \\
HA & Humic acid \\
HOC & Hydrophobic organic compound \\
NP & 4-Nonylphenol \\
OP & 4-tert-Octylphenol \\
PAH & Polycyclic aromatic hydrocarbon \\
PYR & Pyrene \\
SBAC & Sewage sludge-based activated carbon \\
SOM & Soil organic matter
\end{tabular}




\section{Introduction}

Surface runoff from urban areas is a primary cause of flooding and erosion of urban streams, as well as a major source of pollution of receiving water bodies. Bioretention and rain gardens are examples of green infrastructure that help maintain or restore the natural flow pattern of stormwater by collecting and storing the water, allowing it to infiltrate into the ground, removing pollutants and recharging the groundwater table and natural streams (European Commission 2013; US EPA 2014; Waterbucket 2014). Bioretention and rain garden are used interchangeably, but bioretention tends to be used for largerscaled systems with more detailed design criteria. Both systems consist of a shallow, planted depression in the landscape that allows surface runoff from impervious areas to soak into the ground through a medium, usually a native or engineered soil. This reduces peak flows and flow volume, as well as promoting removal of both particulate and dissolved contaminants in stormwater (Davis et al. 2009; Grebel et al. 2013; LeFevre et al. 2014; Muthanna et al. 2007; Trowsdale and Simcock 2011). Metals such as $\mathrm{Cu}$ and $\mathrm{Zn}$ occur in both particulate and dissolved form in polluted stormwater (Camponelli et al. 2010; Morrison et al. 1990). Recent studies show that hydrophobic organic pollutants, including, e.g. polycyclic aromatic hydrocarbons (PAHs), are also present in the colloidal and dissolved phase in stormwater (Brown 2002; Kalmykova et al. 2013; Kalmykova et al. 2014; Zgheib et al. 2011). Studies indicate that, aside from particle sedimentation, sorption followed by biodegradation are the major hydrocarbon removal mechanisms in bioretention and rain gardens, although volatilization and plant uptake are also possible pathways (LeFevre et al. 2014; LeFevre et al. 2012a; Zhang et al. 2014). Given that sorption is a major removal process for organic pollutants, the performance of the bioretention medium is essential. Currently, there are very few performance data for bioretention and rain gardens, especially related to the removal of organic compounds (Davis et al. 2009; DiBlasi et al. 2008; Grebel et al. 2013; LeFevre et al. 2012a; Zhang et al. 2014). Existing studies indicate that these systems are effective in removing organic pollutants from stormwater; for hydrophobic compounds such as petroleum hydrocarbons and lighter PAHs, 80-90\% reduction of the incoming load can be expected (DiBlasi et al. 2008; Hong et al. 2006; LeFevre et al. 2012a).

To further enhance the removal of pollutants from stormwater, amending the bioretention media with biochar, fly-ash and water treatment residuals has been proposed (O'Neill and Davis 2012; Tian et al. 2014; Zhang et al. 2008). However, studies on media amendment to enhance the removal of organic pollutants are to date very limited. The hypothesis is that media amended with efficient adsorbents exhibit limited pollutant migration, and delayed saturation and loss of sorption capacity compared to non-amended media. This would lead to lower media replacement frequency, hence lower costs of maintenance. Contaminated soils amended with activated carbon and biochar exhibit reduced mobility and bioaccumulation of metals (e.g. As, $\mathrm{Cd}, \mathrm{Pb}$ and $\mathrm{Zn}$ ) and organic compounds (e.g. PAHs and the herbicide atrazine) compared to non-amended soils (Beesley and Marmiroli 2011; Bian et al. 2014; Jakob et al. 2012; Wang et al. 2014; Ulrich et al. 2015). In previous research (Björklund and Li 2017), we have shown that activated carbon produced from domestic sewage sludge is an efficient adsorbent for removing hydrophobic organic compounds (HOCs) such as PAHs, phthalates and alkylphenols.

Although activated carbon is very efficient for removal of HOCs from water, the presence of dissolved organic matter (DOM) in stormwater may negatively affect HOC sorption through competition for sorption sites on the adsorbent surface and blockage of pores by the large DOM molecules (Kilduff et al. 1996; Li et al. 2003; Pelekani and Snoeyink 1999; Quinlivan et al. 2005). In previous tests of sewage sludgebased activated carbon (SBAC), batch sorption tests were deemed ineffective due to low water solubility of HOCs and high sorption capacity of SBAC, leading to low saturation of the carbon and little competition between HOCs and DOM. In continuous flow systems, such as column studies, the sorbent is initially only partially loaded with HOCs and DOM, but more HOCs and DOM continuously enter the system, possibly leading to competition for adsorption sites (Li et al. 2003). Testing SBAC in column studies where a continuous inflow of both HOCs and DOM may affect the sorbents' performance is therefore necessary.

The aim of this research was to investigate whether a soilbased bioretention medium amended with SBAC increases the removal efficiency of frequently detected HOCs in stormwater, compared to non-amended medium. The scope of this study is limited to sorption of dissolved HOCs; removal of particle-bound pollutants is excluded. The objectives of the study were to (i) compare the adsorption capacity of SBAC and soil organic matter (SOM) from bioretention medium in batch sorption tests; (ii) compare the removal of HOCs in bioretention medium with and without addition of SBAC using column tests; and (iii) determine the desorption of HOCs from polluted bioretention medium. These objectives are based on the following hypotheses: (i) organic matter in soil, usually $0-5 \% \mathrm{w} / \mathrm{w}$ in bioretention media (Fassman et al. 2013; Rouhi and Schwartz 2007), is often efficient at capturing HOCs and other pollutants (Chefetz et al. 2000; Chiou et al. 1983). However, adsorption onto SBAC is hypothesized to be higher than to SOM due to the large surface area of SBAC (approximately $700 \mathrm{~m}^{2} / \mathrm{g}$ [Björklund and Li 2017]) and microporosity, which is suitable for HOC adsorption (Smith et al. 2009). (ii) Due to the high sorption capacity of SBAC (Björklund and $\mathrm{Li}$ 2017), non-amended medium will reach breakthrough of HOCs prior to SBAC-amended medium; and (iii) sorption of HOCs to soil is reversible, and sorbed pollutants may be 
desorbed due, for example, to changes in soil properties and cotransport with colloidal matter (Badea et al. 2013; Durjava et al. 2007).

\section{Materials and methods}

\section{Studied compounds}

Screening studies indicate that PAHs, phthalates and alkylphenols are ubiquitous in urban runoff and frequently detected in concentrations that exceed European as well as Canadian water quality standards (Björklund et al. 2009; Björklund et al. 2011; Bressy et al. 2012; Clara et al. 2010; Zgheib et al. 2011). Specific organic compounds included in this study are as follows: three PAHs (fluorene, anthracene and pyrene; 2.5, 3 and 4 aromatic rings, respectively); two alkylphenols (4-nonlyphenol and 4-tert-octylphenol); and two phthalates (dibutyl phthalate and di(2-ethylhexyl) phthalate). Selected physical-chemical properties of the compounds are presented in Table 1.

\section{Bioretention medium}

The medium was sampled from a rain garden receiving runoff from a roof and minor surface runoff from a grassed area. The rain garden had been in operation for 1.5 years at the time of sampling. Samples were taken from approximately 50-300 mm below the surface using a clean pail and shovel. The medium, henceforth referred to as soil, an engineered soil marketed under the name Cascade Ecomedia, is developed by Cascade Envirotech (Aldergrove, BC, Canada). This soil was stored in darkness at $4{ }^{\circ} \mathrm{C}$ prior to use in our experiments. In the sieved soil ( $<2 \mathrm{~mm}$ ), almost $90 \%$ of the soil particles are $\leq 250 \mu \mathrm{m}$, $\mathrm{pH}=4.3$, particle density $=2.54 \mathrm{~g} / \mathrm{cm}^{3}$ and loss on ignition $=3.75 \%$ (more details in Supplementary Material and Björklund and Li 2016). Leaching tests (Björklund and Li 2016) revealed that none of the studied HOCs was released from the soil in a detectable amount.

\section{SBAC}

The production of SBAC and the material's characteristics are described in detail in Gong (2013) and Björklund and Li (2017). The carbon source is dried sludge from a domestic sewage treatment pilot plant. The sludge was soaked in the activation agent $\mathrm{ZnCl}_{2}$, and carbonized through pyrolysis at $T_{\text {final }}=500{ }^{\circ} \mathrm{C}$. The finished carbon product was ground and washed with $\mathrm{HCl}$ and distilled water before final drying $\left(105^{\circ} \mathrm{C}\right)$ and storage in amber glass bottles. The $\mathrm{pH}$, surface area and ash content of the activated carbon were $3.4,700 \mathrm{~m}^{2}$ / $\mathrm{g}$ and 9\%, respectively (Björklund and Li 2017).

\section{Chemical standards}

Standards of 4-nonylphenol (85\% content of para-isomers), fluorene, anthracene, pyrene, dibutyl phthalate, di(2ethylhexyl) phthalate, acenaphthene- $\mathrm{d}_{10}$, phenol- $\mathrm{d}_{6}$, benzyl benzoate and phenanthrene- $\mathrm{d}_{10}$ and humic acids (HAs) were purchased from Sigma-Aldrich, and 4-tert-octylphenol was supplied by Fluka. Stock standard solutions of the organic compounds were prepared in toluene obtained from Caledon Laboratories Ltd. (final concentration approximately $5000 \mathrm{ng}$ / $\mu \mathrm{L}$ ), and working standards for spiking water samples were prepared in acetone from Fisher Scientific (final concentration approximately $100 \mathrm{ng} / \mu \mathrm{L}$ ). Acenaphthene- $\mathrm{d}_{10}$ and benzyl benzoate were used as surrogate standards, whereas phenol- $\mathrm{d}_{6}$ and phenanthrene- $\mathrm{d}_{10}$ served as internal standards. Internal and calibration standards of analytes were prepared in toluene. All solutions were stored in amber glass bottles at $-18^{\circ} \mathrm{C}$ until use.

Table 1 Acronyms, CAS identification numbers and selected physico-chemical properties of the organic compounds studied

\begin{tabular}{|c|c|c|c|c|c|}
\hline Chemical name (acronym) & CAS number & MW (g/mol) & Water solubility $^{\mathrm{a}}(\mathrm{mg} / \mathrm{l})$ & $\log K_{\mathrm{ow}}^{\mathrm{b}}$ & $K_{o c}{ }^{\mathrm{b}}$ \\
\hline \multicolumn{6}{|l|}{ Polycyclic aromatic hydrocarbons } \\
\hline Fluorene (FL) & $86-73-7$ & 166 & 1.8 & 4.02 & 4241 \\
\hline Anthracene (ANT) & $120-12-7$ & 178 & 1.3 & 4.35 & 7274 \\
\hline Pyrene (PYR) & $129-00-0$ & 202 & $7.7 \times 10^{-2}$ & 4.93 & 17,180 \\
\hline \multicolumn{6}{|l|}{ Phenols } \\
\hline 4-tert-Octylphenol (OP) & $140-66-9$ & 206 & 19 & 4.12 & 10,290 \\
\hline 4-Nonylphenol (NP) & $84852-15-3$ & 220 & 5.4 & 4.48 & 18,970 \\
\hline \multicolumn{6}{|l|}{ Phthalates } \\
\hline Dibutyl phthalate (DBP) & $84-74-2$ & 278 & 9.9 & 4.57 & 1919 \\
\hline Di(2-ethylhexyl) phthalate (DEHP) & $117-81-7$ & 391 & $2.5 \times 10^{-3}$ & 7.50 & 99,470 \\
\hline
\end{tabular}

${ }^{\text {a } D E F R A ~ 2008 ; ~ E C B ~ 2002, ~ 2004, ~ 2008 ; ~ M a c k a y ~ e t ~ a l . ~} 2006$

${ }^{\mathrm{b}} \log K_{\mathrm{ow}}$ values from KOWWINTM (v1.68) and $K_{o c}$ from KOCWINTM of the EPI Suite ${ }^{\mathrm{TM}}$ (US EPA 2012) 


\section{Extraction and analysis of organic compounds in water samples}

The liquid-liquid extraction (LLE) of HOCs in water is described in detail in Björklund and Li (2015). In short, the HOCs were simultaneously extracted with $3 \times 25 \mathrm{~mL}$ dichloromethane (DCM, from Fisher Scientific), evaporated to dryness with $\mathrm{N}_{2}$, and the extracts were reconstituted with toluene. Extraction of HOCs from soils is described in the "Determination of HOC loads in polluted soils" section.

Internal standards ( phenol- $\mathrm{d}_{6}$ and phenanthrene- $\mathrm{d}_{10}$ ) were added to extracts and calibration solutions before GC-MS analysis. The analytical procedure using GC-MS was similar for both water and soil samples and is described in detail in Björklund and Li (2015). Compounds were identified using gas chromatographic retention times and mass spectral patterns of at least three ions. For quantification, six-point calibration curves were prepared for all target compounds. The concentration range for samples from the batch sorption tests (see the "Batch sorption tests of SBAC and SOM" section) was 2.5-150 and 2.5-50 $\mu \mathrm{g} / \mathrm{L}$ for water and soil samples from the column tests, respectively (see the "Column tests" and "Determination of HOC loads in polluted soils" sections, respectively).

\section{Batch sorption tests of SBAC and SOM}

To compare the sorption capacity of SBAC and SOM, batch sorption tests were performed. The tests were performed similarly to a previous study on SBAC adsorption of HOCs (Björklund and $\mathrm{Li}$ 2017) to achieve comparable results. One hundred and fifty millilitres of ultrapure water (purified with a Synergy UV Milli-Q system from Millipore) was spiked with a mixture of the seven HOCs (Table 1) to final concentration $100 \mu \mathrm{g} / \mathrm{L}$ of each compound. Fifteen milligrammes of SBAC or SOM was contacted with the HOC solution for $24 \mathrm{~h}$ in an end-over-end tumbler. In the SOM samples, a soil mass corresponding to $15 \mathrm{mg}$ OM (derived from the determined organic content, see Supplementary Material) was used. The solid phase was removed by centrifugation at $2000 \times g$ for $10 \mathrm{~min}$. The liquid phase was extracted and analysed by GC-MS (see the "Extraction and analysis of organic compounds in water samples" section). All samples were made in duplicates. For all batches, matrix blanks and a matrix spike were prepared following the same procedure to determine contamination and loss of analytes, respectively.

\section{Column tests}

Three columns were used in the continuous flow tests: two columns with soil amended with $0.5 \%(w / w)$ SBAC and one control column with non-amended soil. The chosen amendment dose has been used by other researchers, e.g. Tian et al. (2014). To ensure a homogenous material, the soil was sieved to remove particles $>2 \mathrm{~mm}$ in nominal size and long plant fibres. Sorption onto the medium occurs during infiltration of stormwater and is a kinetic process, therefore dependent on medium-pollutant contact time, i.e. infiltration rate. Typical bioretention and rain garden infiltration rates are $50-200 \mathrm{~mm} / \mathrm{h}$ (generally approaching $100 \mathrm{~mm} / \mathrm{h}$ ) and soil dry bulk densities are $0.8-2.0 \mathrm{~g} / \mathrm{cm}^{3}$ (generally $1.5 \mathrm{~g} / \mathrm{cm}^{3}$ ) (Greater Vancouver Sewerage and Drainage District 2012; KWL 2012; Rouhi and Schwartz 2007). The soil bulk density was determined according to the cylindrical core method (D7263 [ASTM 2009]) and the moisture content according to D2216 (ASTM 2010). Particle density (specific gravity) was determined using the pycnometer method and volumetric flask method (D854 [ASTM 2014]). All parameters were determined on triplicate samples.

All column components were stainless steel. The interior measures of the columns were as follows: diameter $114 \mathrm{~mm}$ and height $51 \mathrm{~mm}$. A detailed description and schematic of the columns are found in $\mathrm{Li}$ (2011). Prior to use, all components of the column set-ups were washed with detergent and water, followed by acetone rinsing. Height-to-width ratio $<1$ was chosen because increasing the width of the column can reduce the potential of preferential and sidewall flows, which easily occur in columns with high height-to-width ratios, leading to poorer contact between solid material and synthetic stormwater. To further prevent sidewall leakage, the inner walls of the columns were smeared with a thin layer of bentonite slurry (moisture content $200 \%$ ). Porous stones were used at the top and bottom of the columns to prevent preferential flow. The stones were cleaned by sonicating in ultrapure water for $1 \mathrm{~h}$ at room temperature and then boiled for $30 \mathrm{~min}$ to remove air pockets. The soil was compacted in the columns according to D698 (ASTM 2012). The resulting bulk density in the columns was $1.22 \mathrm{~g} / \mathrm{cm}^{3}$, which is within the range, but on the lower end, of observed densities in bioretention and rain gardens. From the bulk and particle density $\left(2.54 \mathrm{~g} / \mathrm{cm}^{3}\right)$, the average pore volume was estimated to be $227 \mathrm{~cm}^{3}$ (Budhu 2007). The SBAC was evenly spread on top of the packed soil layer (i.e. closest to the outlet) in two columns.

The columns were operated at constant upward water flow, which generally leads to a more even flow than downward flow column leaching. The system was fed with synthetic stormwater: to tap water, a humic acid stock was added to a final dissolved organic carbon (DOC) concentration of approximately $20 \mathrm{mg} / \mathrm{L}$, and the working standard of HOCs was added to a final concentration of $50 \mu \mathrm{g} / \mathrm{L}$ of each of the seven HOCs. The synthetic stormwater was prepared twice a day in three pressurized stainless steel containers in series, with a total volume of $20 \mathrm{~L}$ (gravity flow could not be utilized because of practical reasons). The flow rate of the system was controlled by three peristaltic pumps in parallel, connected to the stainless steel containers and the inlet of the columns using Teflon tubing. Each pump was set to $6.4 \mathrm{~mL} / \mathrm{min}$, resulting in an infiltration rate of $44.7 \mathrm{~mm} / \mathrm{h}$. The rate is slightly lower than design recommendations $(50 \mathrm{~mm} / \mathrm{h})$, but was determined by the total volume of the stainless steel containers. Teflon 
tubing was also used at the outlet of the columns to drain effluent water. Effluent water samples were collected in amber glass bottles every $12 \mathrm{~h}$ (corresponding to every 20 pore volume) during $35 \mathrm{~min}$, each sample corresponding to one pore volume. Samples were stored in a cold room at $4{ }^{\circ} \mathrm{C}$ for no longer than 4 days until extraction and GC-MS analysis. For all batches, a matrix spike and a blank were prepared and analysed together with column eluate samples. The experiment was terminated after 28 days, corresponding to 1000 pore volumes, of continuous flow.

Eluate samples from the column study were analysed for HOCs using GC-MS (see the "Extraction and analysis of organic compounds in water samples" section) and DOC using a Lachat Instrument IL 500 TOC analyser. This instrument was later replaced by a Dohrmann Phoenix 8000, UVPersulfate TOC Analyser (see the "The effect of dissolved organic matter on sorption capacity" section).

\section{Desorption of HOCs from polluted soils}

After completion of the column study, soil from the control column was divided into three equally thick $(17 \mathrm{~mm})$ layers. These individual portions were thoroughly mixed prior to moisture content analyses (triplicates of each layer). Desorption of leachable HOCs from each layer was determined following the ISO/ TS 21268-2 standard method (International Organization for Standardization 2007). After $24 \mathrm{~h}$ agitation, the samples (triplicates of each layer) were settled for $10 \mathrm{~min}$, centrifuged at $2000 \times \mathrm{g}$ for $10 \mathrm{~min}$ and filtered through a $934-\mathrm{AH}$ glass fibre filter (Whatman). The HOCs were extracted from soil eluates using the LLE method described in the "Extraction and analysis of organic compounds in water samples" section.

\section{Determination of HOC loads in polluted soils}

The sorbed loads of HOCs in soil were determined on triplicate samples of each layer of the control column soil (see the "Desorption of HOCs from polluted soils" section). The concentration of HOCs $(\mu \mathrm{g} / \mathrm{g})$ in each layer was multiplied by the known mass of dry soil $(\mathrm{g})$ in each layer to achieve the total HOC load (mg) in the control column soil. Extraction of HOCs from soil was based on methods presented by Hollender et al. (2003) and Song et al. (2002). Approximately $2 \mathrm{~g}$ of the moist soil was spiked with $1.0 \mathrm{~mL}$ surrogate standard (acenaphthene$\mathrm{d}_{10}$ and benzyl benzoate in acetone), after which $5 \mathrm{~mL}$ acetone and $25 \mathrm{~mL}$ DCM were added to the vial. The samples were manually shaken for $1 \mathrm{~min}$ and vented to release potential excess gas. The samples were then placed in an ultrasonic bath $\left(40{ }^{\circ} \mathrm{C}\right.$, VWR Scientific Products, Aquasonic, model $50 \mathrm{HT}, 35 \mathrm{kHz}$ ) for $2 \mathrm{~h}$ and inverted every $10 \mathrm{~min}$. The extracts were filtered through $1.5 \mathrm{~g}$ anhydrous $\mathrm{Na}_{2} \mathrm{SO}_{4}$ (placed in baked glass fibre filter from VWR, $1.6 \mu \mathrm{m}$ pore size), evaporated to a few millilitres using a rotavaporator and then, to complete dryness, with a gentle stream of $\mathrm{N}_{2}$. The extracts were reconstituted with $1.00 \mathrm{~mL}$ toluene and internal standard (phenanthrene- $\mathrm{d}_{10}$ and phenol- $\mathrm{d}_{6}$ ) before analysis by GC-MS (same procedure as for water samples). The background concentrations of HOCs in unpolluted soil were determined on duplicate non-spiked soil samples. A solvent blank (no soil) was also extracted using the same procedure.

The efficiency of the extraction was tested by spiking triplicate blank samples (unpolluted soil) with all HOCs in acetone (final concentration $20 \mu \mathrm{g} / \mathrm{g}$ of each HOC). The spiked samples were dried at room temperature before addition of surrogates and initiation of the extraction procedure. The average recoveries of acenaphthene- $\mathrm{d}_{10}$ and benzyl benzoate were 64 and $112 \%$, respectively. In the spiked samples the recoveries of HOCs were as follows: fluorene 47 , anthracene 75 , pyrene 84 , octylphenol 86 , nonylphenol 114, dibutyl phthalate (DBP) 102 and di(2ethylhexyl) phthalate (DEHP) $141 \%$. The low recoveries of acenaphthene- $\mathrm{d}_{10}$ and fluorene may be due to their higher volatility, whereas the high recovery of DEHP may have been caused by contamination problems.

\section{Data analysis}

\section{Statistical analyses}

The program IBM SPSS Statistics 22 was employed to perform statistical analyses, including Pearson's and Spearman's correlations and Mann-Whitney $U$ test. Pearson's correlation represents a linear relationship between two variables and requires normally distributed data. Spearman's rank correlation works by converting each variable into ranks, and is used when data do not meet the assumptions about normality and linearity. Because the logarithm of the partitioning coefficient $K_{\text {ow }}$ is used, correlations involving $K_{\text {ow }}$ are tested using the rank test. The Mann-Whitney $U$ test is used to compare differences between two independent groups when data are not normally distributed. Normality was tested using the ShapiroWilk test: if $p>0.05$, the distribution of data is not significantly different from a normal distribution.

\section{Sorption capacity}

In the batch tests, the sorption capacity at equilibrium, $q_{e}(\mu \mathrm{g} /$ $\mathrm{g}$ ), was determined using

$q_{e}=V \times \frac{C_{0}-C_{e}}{m}$

where $C_{0}$ and $C_{\mathrm{e}}$ are the initial and equilibrium concentrations of the HOCs in the water phase $(\mu \mathrm{g} / \mathrm{L})$, respectively; $V$ is the volume of the solution (L); and $m$ is the weight of the adsorbent $(\mathrm{g})$. 
Breakthrough curves

The outcomes of column studies are often reported using breakthrough curves: a plot with time $(t)$ or pore volume $(V)$ on the $x$-axis and $C / C_{0}$ on the $y$-axis, where $C$ is the HOC concentration in a sample at a specific time or pore volume and $C_{0}$ is the initial HOC concentration $(50 \mu \mathrm{g} / \mathrm{L}$ in this study). The breakthrough time is arbitrarily set; in the current study, we use $C / C_{0}=0.10$, i.e. $10 \%$ of the initial concentration is detected in the effluent.

\section{Estimation of enhanced pollutant removal using SBAC}

One of the hypotheses behind this study is that amendments extend the lifetime of the medium before saturation occurs and pollutant leaching becomes unacceptable. In this example, we used fluorene to calculate the enhanced sorption capacity brought by SBAC, as compared to non-amended soil.

From the column effluent concentrations and applied volume of synthetic stormwater, the difference in removed fluorene loads between the control and SBAC-amended columns was calculated. The SBAC and soil mass in the column were then scaled up to match the SBAC and medium mass in $1 \mathrm{~m}^{2}$ bioretention or rain garden. The assumed medium depth is $0.5 \mathrm{~m}$ (Fassman et al. 2013; KWL 2012), i.e. $1 \mathrm{~m}^{2}$ bioretention or rain garden corresponds to $0.5 \mathrm{~m}^{3}$ soil. The fluorene load removed by $0.5 \%(w / w)$ SBAC amended to $1 \mathrm{~m}^{2}$ bioretention $\left(0.5 \mathrm{~m}^{3}\right)$ was then calculated.

In residential areas, each square metre of bioretention or rain garden is usually connected to a larger contributing watershed than roads with high traffic count, due to the lower percentage of impervious surface. On the other hand, pollutant concentrations are generally lower in residential than in heavily trafficked areas. Two scenarios were therefore simulated: (1) The bioretention receives runoff from a residential area, where the concentration of fluorene is low $(0.05 \mu \mathrm{g} / \mathrm{L})$, the runoff coefficient $=0.35$ and the size of the bioretention surface area is $2 \%$ of the impervious area that drains into the bioretention; and (2) the bioretention receives runoff from a traffic area, where the concentration of fluorene is high $(1 \mu \mathrm{g} / \mathrm{L}),=0.8$ and the size of the bioretention surface area is $10 \%$ of the impervious area that drains into the bioretention. Data on fluorene concentrations, runoff coefficients and impervious/pervious area were obtained from the StormTac database (2016), Tegelberg and Svensson (2013) and Campbell et al. (2013), respectively. Using these assumptions, together with the annual rainfall in Langley, BC, Canada $(1375 \mathrm{~mm})$, the annual runoff volumes and corresponding fluorene loads drained to $1 \mathrm{~m}^{2}$ bioretention in a residential and a traffic area were estimated. Ultimately, the annual fluorene loads estimated from the two scenarios were compared to the removed mass of fluorene in $1 \mathrm{~m}^{2}$ bioretention amended with $0.5 \%$ SBAC.
Theoretical sorption, soil and water distribution estimations

The theoretical maximum mass, $m_{a d s}(\mathrm{mg})$, of HOCs that can be sorbed to the soil is calculated using:

$m_{a d s}=K_{o c} \times f_{o c} \times m_{\text {soil }}$

where $K_{o c}$ is the organic carbon-normalized partition coefficient between soil and water phases; $f_{o c}$ is the mass fraction of soil organic matter content (0.0375); and $m_{\text {soil }}$ is the soil mass (g) in the column. $K_{o c}$ is a literature value derived from $K_{\mathrm{ow}}$ (Table 1).

The desorption coefficient, $K_{\text {des }}(\mathrm{L} / \mathrm{kg})$, is the ratio between the content of the HOC remaining in the soil phase and the mass concentration of the desorbed compound in the aqueous solution, calculated from

$K_{\text {des }}=\frac{m_{s}^{a d s}-m_{a q}^{d e s}}{m_{a q}^{d e s}} \times \frac{V_{T}}{m_{\text {soil }}}$

where $m_{s}^{a d s}(\mu \mathrm{g})$ is the mass of the test compound adsorbed on soil at adsorption equilibrium (i.e. adsorbed load at termination of column experiment); $m_{a q}^{d e s}(\mu \mathrm{g})$ is the mass of the test compound desorbed from soil at desorption equilibrium (i.e. desorbed load at termination of desorption test); $V_{T}(\mathrm{~L})$ is the volume of aqueous phase in contact with the soil during the desorption test; and $m_{\text {soil }}(\mathrm{g})$ is the mass of soil used in the desorption test (OECD 2000). A high $K_{\text {des }}$ value means that the substance is strongly sorbed to soil and organic matter, whereas a low value means that the compound is highly mobile in soil.

\section{Results and discussion}

\section{Batch sorption tests of SBAC and SOM}

The sorption of HOCs contacted with SOM was substantially lower than with SBAC. The differences between initial $\left(C_{0}\right)$ and final concentrations $\left(C_{e}\right)$ of the phthalates DBP and DEHP in batch tests with soil were only a few microgrammes per litre, i.e. very low sorption capacity. The soil's sorption capacities for nonylphenol and octylphenol were almost five $\left(q_{e, S O M}=200 \mu \mathrm{g} / \mathrm{g}\right)$ and eight $\left(q_{e, S O M}=120 \mu \mathrm{g} / \mathrm{g}\right)$ times lower, respectively, than SBAC's capacity $\left(q_{e, S B A C} \geq 900 \mu \mathrm{g} / \mathrm{g}\right.$ for both alkylphenols) (Björklund and Li 2016). The average adsorption capacities for all HOCs onto SOM were significantly lower than onto SBAC (Mann-Whitney $U=1.00, p=0.003$, two-tailed). The highest removal using soil was observed for the PAHs, with $70 \%$ of pyrene being removed, corresponding to $q_{e, S O M}=660 \mu \mathrm{g} / \mathrm{g}$, whereas approximately $30 \%$ of fluorene and anthracene were removed, corresponding to $q_{e, S O M}=270$ and $200 \mu \mathrm{g} / \mathrm{g}$, respectively. These results suggest that SOM 
has potential to sorb large quantities of HOCs, due to its sorption capacity and abundance $(\leq 5 \% \mathrm{w} / \mathrm{w})$ in some engineered soils used as bioretention medium. In fact, SOM is dominated by apolar groups, such as aliphatic and aromatic moieties, which are important sorption sites for HOCs (Kyoichi 1987). However, the sorption capacity of SBAC is superior to that of SOM, due to the abundance of hydrophobic sites and high surface area (Björklund and Li 2017). Hence, SBAC has the potential to add supplementary pollutant removal and storage if amended to bioretention and rain garden soils.

\section{Removal of HOCs in column tests}

\section{Breakthrough curves}

Breakthrough $\left(C / C_{0}=0.10\right)$ was reached at very different pore volumes for different compounds. As a rule, the least hydrophobic compound of each group-fluorene, octylphenol and DBP $\left(\log K_{\text {ow }}=4.02-4.57\right)$ - exhibited shorter breakthrough times and were observed in higher concentrations in the effluent than the more hydrophobic compounds. This trend is illustrated in the breakthrough curves of fluorene, nonylphenol and pyrene (Fig. 1). Breakthrough curves of anthracene, octylphenol and DBP are found in the Supplementary Material, Fig. S2. Breakthrough of fluorene was reached at 200 pore volumes (Fig. 1a), after which effluent concentrations ranged between 10 and $30 \%$ of the influent concentration $(50 \mu \mathrm{g} / \mathrm{L})$. Octylphenol reached $C / C_{0}=0.10$ within 100 pore volumes in all three columns, which is the shortest breakthrough time of all compounds tested (Fig. S2). The effluent concentrations of DBP exhibited great variations; breakthrough was reached after approximately 180 pore volumes, and reached $C / C_{0}=0.30-0.40$ between pore volumes 450 and 650, but was subsequently stabilized at $C / C_{0}=0.05-0.20$, with the higher effluent concentrations found for the control column (Fig. S2). Octylphenol showed similar behaviour to DBP from pore volume 450 and onwards. The time-limited increase in effluent concentrations of DBP and octylphenol may depend on required equilibration time before sorption reached its capacity, as previously reported, e.g. by Ulrich et al. (2015). During the entire course of the experiment, breakthrough (0.10) was never reached (outliers excepted) for anthracene (Fig. S2), pyrene and nonylphenol (Fig. 1a, c). The phthalate DEHP, which is the most hydrophobic compound studied ( $\log K_{\mathrm{ow}}=7.5$ ), exhibited inconclusive results. This could be a result of contamination of samples, which is commonly observed for phthalates due to their ubiquitous occurrence in plastic materials. In addition, because of the low water solubility of DEHP (Table 1), this substance may attach to labware surfaces or form emulsions in water, which is not evenly distributed in the columns, leading to variations in influent and effluent concentrations (Julinová and Slavík 2012). Accordingly, DEHP was excluded from further water

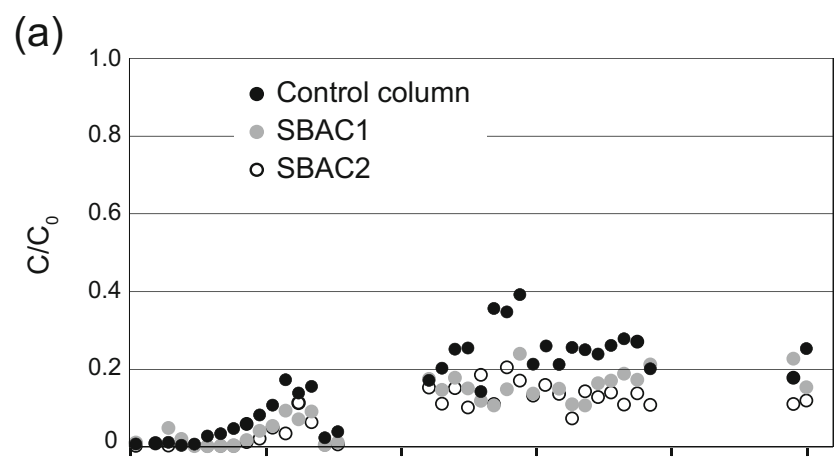

(b)

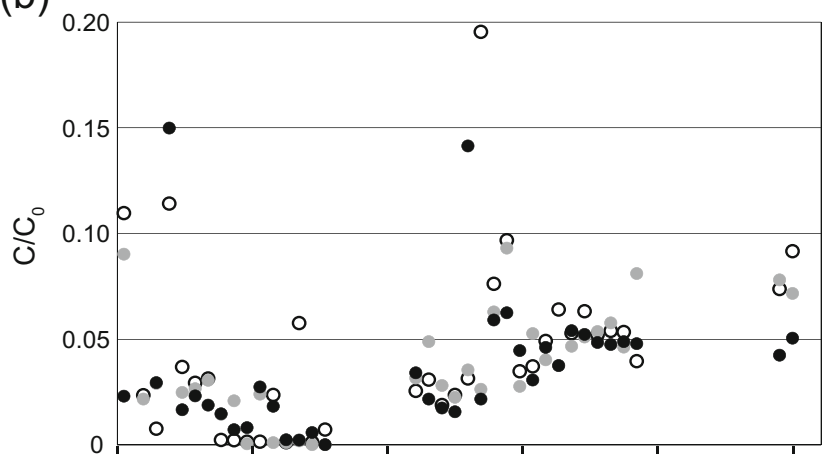

(c)

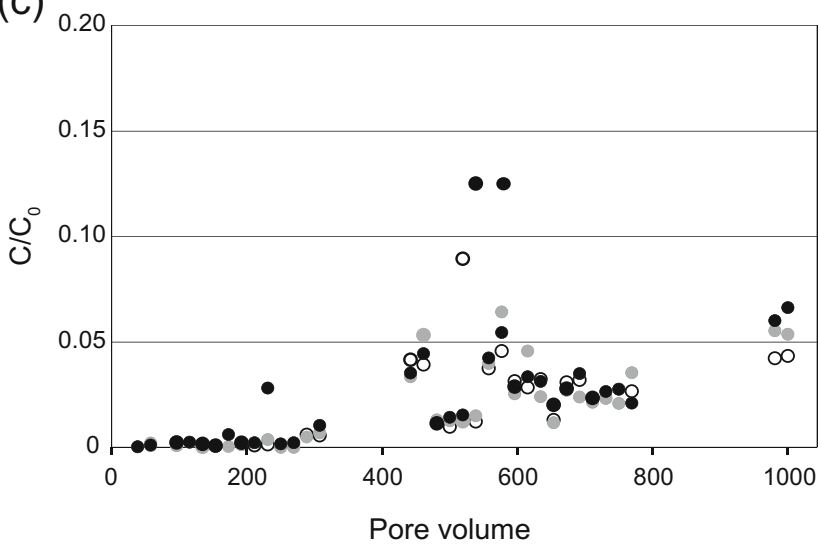

Fig. 1 Breakthrough curves of a fluorene $\left(\log K_{\text {ow }}=4.02\right)$, b nonylphenol $\left(\log K_{\mathrm{ow}}=4.48\right)$ and $\mathbf{c}$ pyrene $\left(\log K_{\mathrm{ow}}=4.93\right)$ indicating the effluent-inlet concentration ratio $\left(C / C_{0}\right)$ as a function of the number of pore volumes passed through two columns with added SBAC $(0.5 \% \mathrm{w} / \mathrm{w})$ and the control column. Each pore volume corresponds to $227 \mathrm{~mL}$. Note the different scales on the $y$-axis

data analysis. In general, the average $C / C_{0}$ (all pore volumes) for HOCs in all three columns correlated well with compound $\log K_{\text {ow }}$ (Spearman's $\rho=-0.638$ to -0.725 ).

The difference in effluent concentrations was not statistically different between the two columns with added SBAC (Mann-Whitney $U=545-626, p=0.140-0.804$, two-tailed). However, effluent concentrations of fluorene, octylphenol and anthracene were significantly higher in the control column than in the two columns with SBAC (Mann-Whitney $U=355-451, p=0.001-0.027$, two-tailed). These results 
indicate that SBAC amended to bioretention and rain garden soil may enhance the removal of dissolved HOCs and/or prevent leaching of already sorbed pollutants. Amendment of SBAC appears to have a particular positive effect on the removal of moderately hydrophobic HOCs $\left(\log K_{\mathrm{ow}}=4.02-\right.$ 4.35). The reason for this observation could be that the moderately hydrophobic compounds do not exhibit as strong sorption to SOM as compounds of higher $\log K_{\text {ow }}$, e.g. pyrene, which was shown in the batch adsorption tests (see the "Batch sorption tests of SBAC and SOM" section). The highly hydrophobic compounds are removed to a large degree by the SOM alone, whereas the less hydrophobic compounds are more mobile in the soil bed, and SBAC is an important complement to further reduce their effluent concentrations.

Bioretention and rain gardens are usually designed to be drained within 24 to $72 \mathrm{~h}$ to prevent saturated conditions in the medium. The bed is drained to provide storage for back-toback rain events, suitable habitat for vegetation and wet-dry cycling to promote different removal processes (Grebel et al. 2013; LeFevre et al. 2014). In this study, however, a continuous flow system was used, i.e. saturated conditions, to facilitate the experimental procedure and promote optimum contact between media and synthetic stormwater. The soil in the columns can be considered "ideally packed", and water is assumed to be "ideally distributed" over the soil bed (due to upward water flow, use of porous rocks to evenly distribute incoming water and bentonite clay to prevent preferential flow along column walls). All these factors contribute to optimizing the contact between water and soil, i.e. a "best case scenario". In addition, by using continuous flow through the medium, crack formation due to drying is avoided; consequently, channelling is avoided. In operating bioretention and rain gardens, channelling along plant roots and preferential flow paths is inevitable, leading to more or less limited contact between water and soil, and hence to limited sorption of pollutants onto soil particles and SBAC. On the other hand, one of the most common maintenance concerns for bioretention and rain gardens is clogging of media caused by fine sediment and soil compaction. Plant roots are essential in macropore formation in the media, helping to maintain the infiltration rate, aerate the soil and minimize compaction (Barrett et al. 2013).

\section{The effect of dissolved organic matter on sorption capacity}

In a previous study, the maximum adsorption capacity of SBAC was estimated to be at least $85 \mathrm{mg} / \mathrm{g}$ for a mixture of HOCs (Björklund and Li 2017). In the current study, the applied load of HOCs to each column during the course of the experiment corresponds to approximately $5.25 \mathrm{mg}$ HOCs per $\mathrm{g}$ of SBAC, i.e. only $6 \%$ of the expected maximum adsorption capacity. Comparably low sorption of HOCs to SBAC in columns may be attributed to competition from organic matter leaching from the soil bed, observed primarily at the startup of the column experiments (Fig. 2). Soil organic matter contains a large portion of soluble, transformed material, called humic substances (Kyoichi 1987), which include both hydrophobic domains (e.g. non-polar aliphatic and aromatic moieties) and hydrophilic functional groups (e.g. polar phenolic and carboxylic moieties). The non-polar surface of activated carbon may interact with the non-polar part of humic substances. Efficient sorption of humic substances to activated carbon was shown in previous studies (Daifullah et al. 2004; Kilduff et al. 1996). We hypothesize that humic acids in the synthetic stormwater $(20 \mathrm{mg} \mathrm{DOC} / \mathrm{L})$ and SOM released from the soil $(\leq 80 \mathrm{mg}$ $\mathrm{DOC} / \mathrm{L}$ ) lead to early saturation of the SBAC, and hence lower HOC adsorption than expected based on a previous study (Björklund and Li 2017). Unfortunately, HOC and DOC effluent concentrations could not be correlated since the DOC instrument was not able to give correct results for some of the batches run. This problem was discovered half-way through the experiment when many of the previous samples had already been discarded or were too old to be re-analysed.

Another column study was set up following the experiments with HOCs, to study the release of DOC from the soil bed (with a new instrument used for DOC analysis). The setup and the soil used were exactly the same as in the described column tests (see the "Column tests" section), with the exception that tap water (not synthetic stormwater) was fed to the columns. Figure 2 shows that the release of DOC was elevated at the beginning of the experiment, and stabilized at $<5 \mathrm{mg} / \mathrm{L}$ from pore volume 140 until the end of the experiment (35 days). This observation was expected, as less and less soluble organic matter was available for leaching from the soil. This gradual decrease in DOC leaching over time was also observed in column tests of peat and compost (Kalmykova et al. 2010; Mullane et al. 2015), whereas

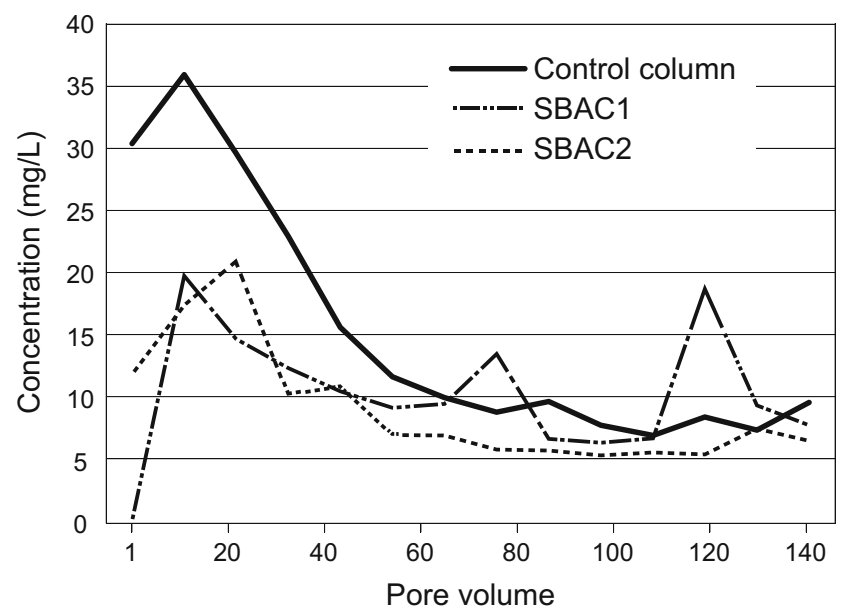

Fig. 2 Concentrations of dissolved organic carbon (DOC $[\mathrm{mg} / \mathrm{L}])$ in effluent water from columns with added SBAC and control column without SBAC in the first 140 pore volumes ( 7 days) of the experiment. Each pore volume corresponds to $227 \mathrm{~mL}$. No DOC was added to the columns; the graph illustrates DOC leached from the soil 
operating bioretention and rain gardens receive new DOC inputs with stormwater and degraded plants. Figure 2 shows the difference in DOC effluent concentrations between the two columns with added SBAC $(\leq 20 \mathrm{mg} / \mathrm{L})$ and the control column without SBAC $(\leq 35 \mathrm{mg} / \mathrm{L})$. Effluent DOC minimum, average and maximum concentrations were higher for the control column compared to SBAC-amended columns. These results suggest that a large portion of the released SOM was adsorbed by SBAC, thereby occupying adsorption sites on the carbon surface and inhibiting the sorption of HOCs (Li et al. 2003; Newcombe et al. 2002). This hypothesis is strengthened by results from a previous study, showing that SBAC can adsorb at least $20 \mathrm{mg}$ DOC (in the form of technical HA) per gram SBAC (Björklund and Li 2017).

Because the tested HOCs only have limited polarity (alkylphenols and phthalates), it may be assumed that these HOCs are more strongly bound to the non-polar SBAC than are humic substances. In fact, our previous studies show that when competition for adsorption sites on SBAC becomes a factor, hydrophobicity plays an important role in the adsorption process: More hydrophobic compounds are removed to a higher degree by SBAC than compounds with lower log $K_{\text {ow }}$ (Björklund and Li 2017). Although SBAC may favour sorption of HOCs, abundant humic substances are strong competitors. Sorption of organic pollutants may, however, take place on both SBAC and SOM, as shown in the batch tests. Another possible pathway for organic pollutants in the columns are to bind to humic substances sorbed onto the SBAC surface, and thereby become immobilized (Wen et al. 2013). However, this hypothesis has not been tested in the current study.

\section{HOCs in polluted column soils}

\section{HOC concentrations and loads in column soil}

As expected, the highest concentrations and the highest loads of HOCs were found in the soil layer closest to the column inlet (Fig. $3 \mathrm{a}$ and $\mathrm{b}$, respectively). The HOC concentrations show strong correlation to compound $\log K_{\mathrm{ow}}$ in the inlet and middle layer (Spearman's $\rho=0.786$ and 0.857 , respectively), but only moderate correlation in the outlet layer $(\rho=0.536)$. Approximately $40-70 \%$ of the total load of each HOC was trapped in the first $17 \mathrm{~mm}$ of the soil, whereas 5-27\% of the load was found in the layer closest to the outlet. The less hydrophobic compounds tend to migrate to a higher degree in the soil than the most hydrophobic compounds: Of all HOCs, fluorene exhibited the highest load portion in the layer closest to the outlet (27\%), followed by DBP and anthracene (20\%), whereas pyrene exhibited the lowest portion in the outlet layer $(5 \%)$. This trend explains why $\mathrm{HOC}$ concentrations in the outlet layer were only moderately correlated to $\log K_{\mathrm{ow}}$. These results compare to a field study on PAHs in rain gardens performed by DiBlasi et al. (2008): Most of the PAH retention appeared to take place in

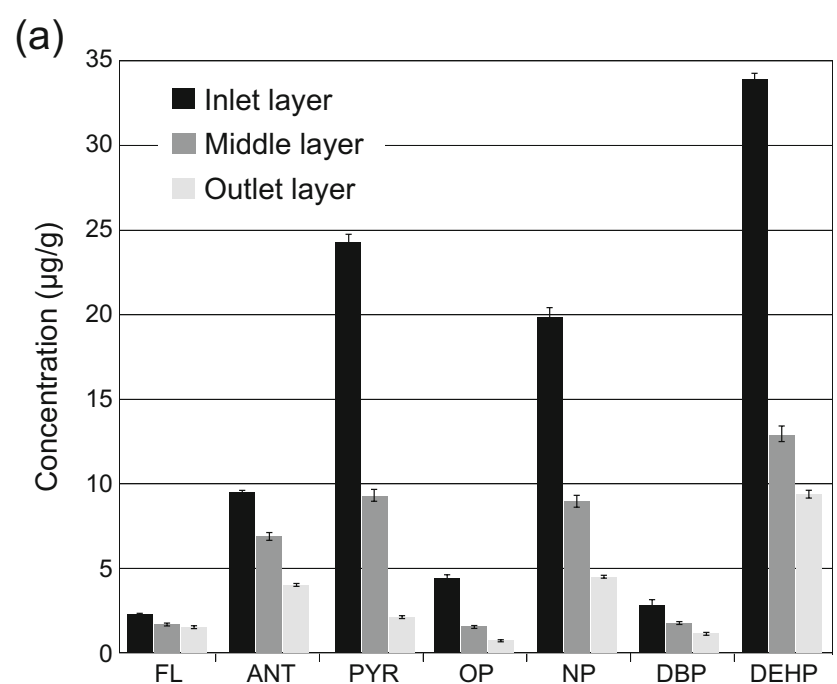

(b)

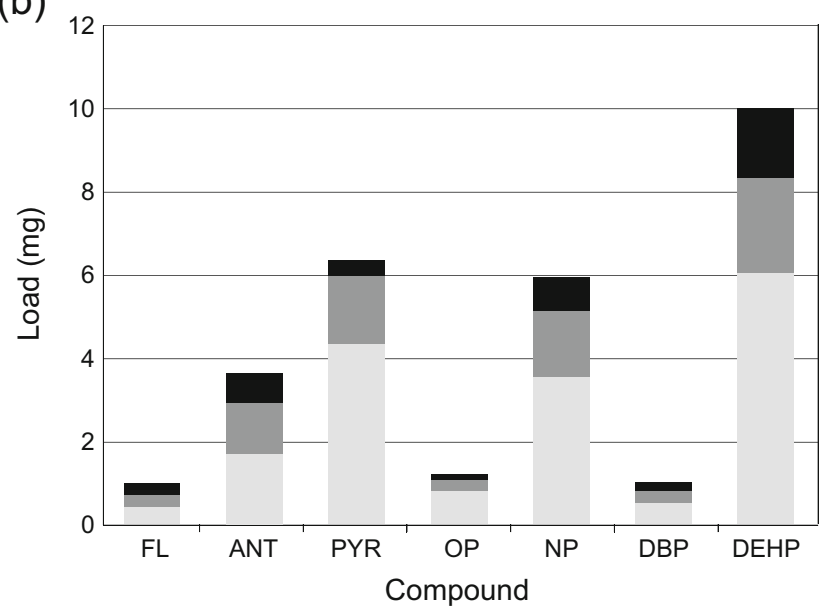

Fig. 3 a Concentrations $(\mu \mathrm{g} / \mathrm{g})$ and $\mathbf{b}$ loads $(\mathrm{mg})$ of HOCs in three separated soil layers (inlet layer $0-17 \mathrm{~mm}$; middle layer $18-34 \mathrm{~mm}$; and outlet layer 35-51 mm). Errors bars illustrate the standard error of the mean concentration in each layer (determined on triplicate samples)

the surficial soil layers through sorption and particle capture. It should be noted that the rain garden had been in operation for less than 3 years when DiBlasi et al. (2008) performed their study. Similarly, Dierkes and Geiger (1999) found that PAH concentrations were generally highest in the upper $10 \mathrm{~cm}$ of roadside soil. However, at some sites, PAH concentrations did not decrease with soil depth $(\leq 30 \mathrm{~cm})$. Murakami et al. (2008) performed column infiltration studies with artificial stormwater and discovered that when the soil layer thickness was increased from 20 to $50 \mathrm{~cm}$, the PAH removal efficiency increased from 17 to $56 \%$, suggesting substantial vertical migration of PAHs. In addition, Strömvall et al. (2006) detected elevated concentrations of semivolatile organic compounds and PAHs to a depth of 1.0 and $1.5 \mathrm{~m}$, respectively, in soil sampled from road ditches. The authors proposed that this unexpected vertical transport of organic pollutants in the soil may be due to colloid-facilitated transport. In the current study, DOC in the form of technical humic acids 
was added to the synthetic stormwater, together with HOCs. The contact time between HAs and HOCs before application to soil columns ranged between 0 and $12 \mathrm{~h}$ (batches of stormwater were prepared twice a day). This may be less than the time needed for dissolved HOCs to equilibrate with HA colloids to form complexes (van de Kreeke et al. 2010). Assuming that the contact time is too short to form HA-HOC colloids to the same extent as in natural stormwater (Brown 2002; Kalmykova et al. 2013), the colloid-facilitated transport, i.e. the migration, of HOCs is underestimated in the column tests. The current study (Fig. 3), together with results from Strömvall et al. (2006) and Murakami et al. (2008), suggests that migration of HOCs through the medium bed (usually $0.5 \mathrm{~m}$ ) may occur over the lifetime of a bioretention or rain garden. Furthermore, greater migration can be expected for less hydrophobic organic pollutants that are dissolved or for HOCs attached to colloids, since they may not be sorbed to or physically retained by the soil particles.

Both octylphenol and DBP exhibited lower loads in the polluted soil than expected from their respective $\log K_{\text {ow }}$ values (Fig. 3b). It is possible that the compound groups (PAHs, phenols and phthalates) sorbed with different intensities to the SOM depending on various physical-chemical and steric characteristics. However, there were too few compounds in each group to draw any conclusions on this matter. The total soil load of each compound is negatively correlated to average concentrations in the columns' effluent water (Spearman's $\rho=-0.600$ to -0.771 ), provided that DEHP effluent concentrations are neglected.

The mass of HOCs sorbed to the soil make up only 10-50\% of the calculated theoretical maximum mass, $m_{\text {ads }}$ (Eq. 2), that can be sorbed to the soil based on the SOM content (Table 2). This suggests that the soil was not saturated with HOCs in the column experiments, so that further sorption was possible. In addition, $C / C_{0}=1$ was not reached for any of the HOCs (Fig. 1, Fig. S2), strengthening this hypothesis. The theoretical remaining sorption capacity (Table 2) did not follow a strong trend with hydrophobicity or actual sorbed mass in soil, implying that sorption is not simply explained by SOM content or compound hydrophobicity.

\section{Desorption of HOCs from polluted soil}

The desorbed loads of HOCs, following the ISO/TS 21268-2 standard method, were compared to the total loads of HOCs in polluted column soil to determine the percentage of desorption (Table 2). In general, the percentage desorption of HOCs was low (1.2-4.7\%) compared to many other desorption studies of organic pollutants in soil, and the HOC sorption to soil cannot be considered reversible (Delle Site 2001; OECD 2000). The desorbed loads $(\mu \mathrm{g})$ were correlated to the total load of HOCs in soil (Pearson's $r=0.702$ ), i.e. the initial mass of HOCs available for desorption, and to compound $\log K_{\text {ow }}$ (Spearman's $\rho=0.631$ ).

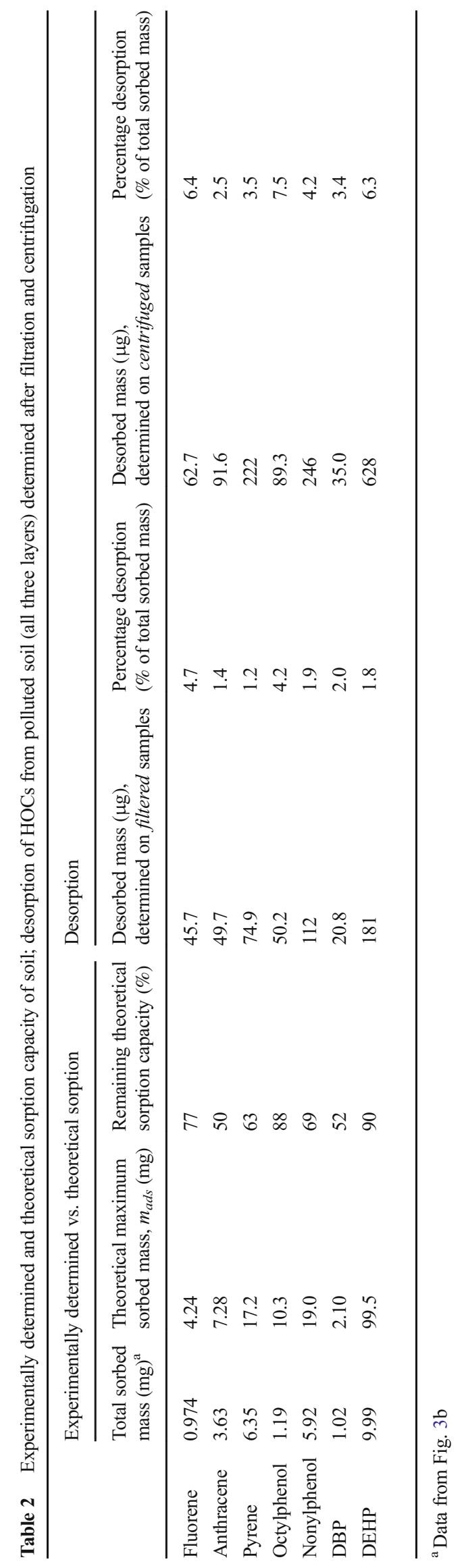


In the current study, the desorbed portion was centrifuged, followed by filtration ( $1.5 \mu \mathrm{m}$ pore size), before extraction and analysis (according to ISO/TS 21268-2). For comparison, centrifuged samples (non-filtered) were also analysed for HOC concentrations. Centrifugation $(2000 \times \mathrm{g}, 10 \mathrm{~min})$ led to separation of settleable solids. The TOC (total organic carbon) concentrations were 14.0 and $50.9 \mathrm{mg} / \mathrm{L}$, respectively, for filtered and centrifuged samples. The difference in $\log K_{d e s}$ for HOCs between centrifuged and filtered samples is illustrated in Fig. 4. $K_{d e s}$-values for DEHP were much lower (i.e. more mobile) than expected from the compound's $\log K_{\mathrm{ow}}$, especially in the centrifuged samples. In general, the desorbed HOC loads in centrifuged samples were $27 \%$ (fluorene) to $71 \%$ (DEHP) higher than in filtered samples (Table 2): This implies that a large portion of the most hydrophobic HOCs are sorbed to particles $>1.5 \mu \mathrm{m}$ (the filter pore size). Brown (2002) studied the partition of PAHs in stormwater particulate, colloidal and truly dissolved phases and came to the conclusion that, contrary to what can be expected from the $\log K_{\text {ow }}$ of PAHs, the importance of the colloidal phase decreased for the more hydrophobic compounds $\left(\log K_{\text {ow }}>4.5\right)$ because the organic carbon in the particulate phase is a better sorbent. Based on this principle, we suggest that DEHP and other highly hydrophobic HOCs are principally sorbed to the organic matter in particles and that sorption to colloids is more important for HOCs of lower hydrophobicity. These results suggest that the cut-off for particle and/or colloid separation greatly affects outcome of desorption tests.

The least hydrophobic compounds fluorene and octylphenol exhibited the lowest $K_{\text {des }}$ (Fig. 4), i.e. the most mobile compounds in soil. These data support the previously presented hypothesis (see the "Removal of HOCs in column tests" section), which the less hydrophobic HOCs exhibit weaker sorption to the SOM. Hence, SBAC plays a larger role in removal of these compounds in the column tests.

The main removal processes of organic pollutants in bioretention and rain gardens, adsorption and biodegradation

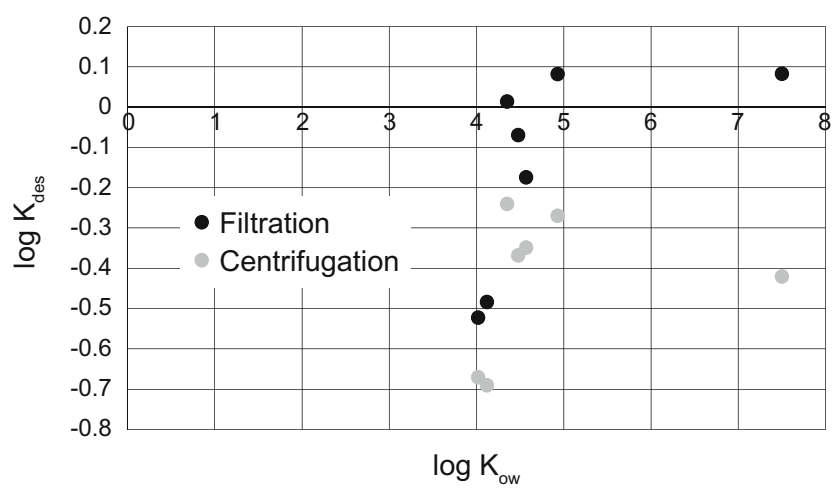

Fig. 4 Logarithm of desorption coefficient, $\log K_{d e s}$, related to the hydrophobicity, $\log K_{\text {ow }}$, of the seven organic compounds investigated. The relationship is shown for filtered $(1.5 \mu \mathrm{m}$ pore size $)$ and centrifuged $(2000 \times g, 10 \mathrm{~min})$ eluates take place mainly during wet and longer dry periods, respectively (LeFevre et al. 2014; Murakami et al. 2008). Zhang et al. (2014) showed that dry periods need to exceed at least $10 \mathrm{~h}$ for biodegradation to occur and that days to weeks may be necessary for degradation of compounds with low degradation rate. Consequently, in the continuous flow columns, sorption is promoted and little or no biodegradation is expected. Desorption data suggest that the HOCs are strongly bound to SOM (Table 2), resulting in low bioavailability and therefore limited opportunity for biodegradation (LeFevre et al. 2012b). Low desorption of HOCs also leads to limited regeneration of sorption sites and opportunities for other pollutants to find available sorption sites.

In planted bioretention and rain gardens, root exudates released from plants may play a role in the desorption of HOCs from soils. Root exudates contain substances such as organic acids, phenolic compounds, polysaccharides, and humic compounds, which are known to increase desorption of HOCs (Gao et al. 2010; LeFevre et al. 2013). Studies show that plant root exudates can abiotically alter and enhance desorption of the PAHs naphthalene, pyrene and phenanthrene from soil, although it is not known which mechanisms are behind the alteration. However, as highlighted by Grebel et al. (2013), the relevance of plant root exudates, and linked enhanced desorption and bioavailability, to stormwater contaminants and conditions is unknown.

\section{SBAC-enhanced sorption}

As an example, fluorene was used to estimate the supplementary sorption capacity of SBAC that may be added to amended soil (see the "Estimation of enhanced pollutant removal using SBAC" section). By adding $0.5 \%(w / w)$ SBAC to $1 \mathrm{~m}^{2}$ bioretention $\left(0.5 \mathrm{~m}^{3}\right.$ soil), almost $1 \mathrm{~g}$ fluorene can be removed, in addition to the load removed by soil. In the simulated area (Surrey, BC, Canada), each square metre of bioretention is assumed to annually receive 110 and $1200 \mathrm{~m}^{3}$ runoff in traffic and residential areas, respectively. This runoff is assumed to carry $110 \mathrm{mg}$ (traffic) and $60 \mathrm{mg}$ (residential) fluorene to $1 \mathrm{~m}^{2}$ of bioretention. Given these loads, $0.5 \%(w / w)$ SBAC amendment to $1 \mathrm{~m}^{2}\left(0.5 \mathrm{~m}^{3}\right)$ bioretention may sorb as much fluorene as the accumulated fluorene load transported with 17 years (residential) and 9 years (traffic) of runoff volumes.

The synthetic stormwater used in the column studies is a much less complex solution than natural stormwater, which contains a wide spectrum of organic pollutants; oil and grease; metals such as $\mathrm{Zn}, \mathrm{Pb}, \mathrm{Cu}, \mathrm{Ni}$ and $\mathrm{Cd}$; nutrients; organic and inorganic colloids; and dissolved compounds, as well as particles. Particles and thereto bound pollutants are expected to be trapped in the very top layer of bioretention and rain garden media (DiBlasi et al. 2008; LeFevre et al. 2014; Murakami et al. 2008). However, many of the dissolved pollutants compete for adsorption sites on the SBAC and contribute to 
saturation of the media. This suggests that the column study is a "best-case scenario" with low competition for adsorption sites, and shorter saturation time of the SBAC should be expected for natural stormwater. Although based on simplified calculations of the supplementary sorption capacity added by SBAC, the results suggest that SBAC may extend the lifetime of a bioretention or rain garden, possibly by approximately 10-20 years, before media saturation occurs.

\section{Conclusions}

Batch adsorption studies show that SBAC has a significantly higher adsorption capacity of selected hydrophobic organic compounds than soil organic matter: Approximately five to eight times higher HOC mass is sorbed to SBAC than to SOM. This difference is assumed to depend on the abundance of hydrophobic sorption sites, in addition to high surface area and great microporosity of SBAC. The column tests indicate, however, that SBAC-amended soil is more efficient in removing moderately hydrophobic compounds, e.g. fluorene, octylphenol, and anthracene, than very hydrophobic compounds. Desorption tests revealed that the HOCs are generally strongly sorbed to the soil particles; the higher the hydrophobicity, the stronger is the sorption to SOM. In addition, more hydrophobic compounds exhibited stronger sorption to particles $>1.5 \mu \mathrm{m}$, whereas less hydrophobic compounds appear to have attached to small particles and colloids. These results all point towards the conclusion that less hydrophobic HOCs exhibit weaker sorption to the SOM, i.e. higher risk of migration through soil beds and that SBAC played a larger role in the removal of these compounds in the column tests. The addition of as little as $0.5 \%(w / w)$ SBAC may extend bioretention media lifetime by approximately $10-20$ years before saturation occurs with the less hydrophobic compounds. However, HOCs are competing with organic colloids for SBAC sorption sites. Column tests revealed that a large portion of the released SOM is adsorbed by SBAC, which may lead to early saturation of SBAC sorption sites. In addition, organic colloids present in stormwater may sorb HOCs and facilitate their transport through the soil bed.

Future studies should focus on the migration of HOCs through the medium bed, as it determines the lifetime of the bioretention and rain garden before leaching of HOCs becomes unacceptable. Although the highest HOC concentrations and loads were found in the first (upper) centimetres of the soil bed, migration of pollutants through the bed cannot be ruled out due to poor pollutant-soil contact in operating systems and colloid-facilitated transport of HOCs through the soil, which is assumed to be of importance in natural stormwater where organic colloids and compounds have enough time to equilibrate and form complexes.
Acknowledgements The Swedish Research Council Formas (grant 245-2012-1607), the Natural Sciences and Engineering Research Council of Canada (NSERC, grant EGP 454264-13) and the Olof och Ollie Ericsson Stiftelse för vetenskaplig forskning are gratefully acknowledged for funding this research. The authors sincerely thank the people at Kerr Wood Leidal for their input on project outline as well as help with sampling and providing data. We wish also to acknowledge the contributions to the laboratory work by students Kristina Sutherland, Richie Chin and Bojun Lei. We also sincerely thank Paula Parkinson and Timothy Ma for laboratory assistance.

Open Access This article is distributed under the terms of the Creative Commons Attribution 4.0 International License (http:// creativecommons.org/licenses/by/4.0/), which permits unrestricted use, distribution, and reproduction in any medium, provided you give appropriate credit to the original author(s) and the source, provide a link to the Creative Commons license, and indicate if changes were made.

\section{References}

ASTM (2009) D7263 standard test methods for laboratory determination of density (unit weight) of soil specimens. ASTM International, West Conshohocken, PA. doi:10.1520/D7263-09

ASTM (2010) D2216 standard test methods for laboratory determination of water (moisture) content of soil and rock by mass. ASTM International, West Conshohocken, PA. doi:10.1520/D2216-10

ASTM (2012) D698 standard test methods for laboratory compaction characteristics of soil using standard effort (12 $400 \mathrm{ft}-\mathrm{lbf} / \mathrm{ft}^{3}$ (600 $\left.\mathrm{kN}-\mathrm{m} / \mathrm{m}^{3}\right)$ ). ASTM International, West Conshohocken, PA. doi:10. 1520/D0698-12E02

ASTM (2014) D854 standard test methods for specific gravity of soil solids by water pycnometer. ASTM International, West Conshohocken, PA. doi:10.1520/D0854-14

Badea S-L, Lundstedt S, Liljelind P, Tysklind M (2013) The influence of soil composition on the leachability of selected hydrophobic organic compounds (HOCs) from soils using a batch leaching test. J Hazard Mater 254-255:26-35. doi:10.1016/j.jhazmat.2013.03.019

Barrett ME, Limouzin M, Lawler DF (2013) Effects of media and plant selection on biofiltration performance. J Environ Eng 139:462-470. doi:10.1061/(ASCE)EE.1943-7870.0000551

Beesley L, Marmiroli M (2011) The immobilisation and retention of soluble arsenic, cadmium and zinc by biochar. Environ Pollut 159: 474-480. doi:10.1016/j.envpol.2010.10.016

Bian R, Joseph S, Cui L, Pan G, Li L, Liu X, Zhang A, Rutlidge H, Wong S, Chia C, Marjo C, Gong B, Munroe P, Donne S (2014) A threeyear experiment confirms continuous immobilization of cadmium and lead in contaminated paddy field with biochar amendment. J Hazard Mater 272:121-128. doi:10.1016/j.jhazmat.2014.03.017

Björklund K, Li LY (2015) Evaluation of low-cost materials for sorption of hydrophobic organic pollutants in stormwater. J Environ Manag 159:106-114. doi:10.1016/j.jenvman.2015.05.005

Björklund K, Li LY (2016) Sorption of DOM and hydrophobic organic compounds onto sewage-based activated carbon. Water Sci Technol 74:852-860. doi:10.2166/wst.2016.240

Björklund K, Li LY (2017) Adsorption of organic stormwater pollutants onto activated carbon from sewage sludge. J Environ Manag 197: 490-497. doi:10.1016/j.jenvman.2017.04.011

Björklund K, Palm Cousins A, Strömvall AM, Malmqvist PA (2009) Phthalates and nonylphenols in urban runoff: occurrence, distribution and area emission factors. Sci Total Environ 407:4665-4672. doi:10.1016/j.scitotenv.2009.04.040 
Björklund K, Strömvall AM, Malmqvist PA (2011) Screening of organic contaminants in urban snow. Water Sci Technol 64:206-213. doi:10. 2166/wst.2011.642

Bressy A, Gromaire MC, Lorgeoux C, Saad M, Leroy F, Chebbo G (2012) Towards the determination of an optimal scale for stormwater quality management: micropollutants in a small residential catchment. Wat Res 46:6799-6810. doi:10.1016/j.watres.2011.12.017

Brown JN (2002) Partitioning of chemical contaminants in urban stormwater. Doctoral thesis, University of Otago, Dunedin, New Zealand. Retrieved from http://hdl.handle.net/10523/5872

Budhu M (2007) Soil mechanics and foundations, 2nd edn. Wiley, Hoboken, NJ

Campbell C, Johnston C, Lee D, Zabil D, Morgan L, Pour S (2013) Top ten design considerations for rain gardens. Proc Water Environment Fed 2013:1501-1511. doi:10.2175/193864713813673497

Camponelli KM, Lev SM, Snodgrass JW, Landa ER, Casey RE (2010) Chemical fractionation of $\mathrm{Cu}$ and $\mathrm{Zn}$ in stormwater, roadway dust and stormwater pond sediments. Environ Pollut 158:2143-2149. doi:10.1016/j.envpol.2010.02.024

Chefetz B, Deshmukh AP, Hatcher PG, Guthrie EA (2000) Pyrene sorption by natural organic matter. Environ Sci Technol 34:2925-2930. doi:10.1021/es9912877

Chiou CT, Porter PE, Schmedding DW (1983) Partition equilibriums of nonionic organic compounds between soil organic matter and water. Environ Sci Technol 17:227-231. doi:10.1021/es00110a009

Clara M, Windhofer G, Hartl W, Braun K, Simon M, Gans O, Scheffknecht C, Chovanec A (2010) Occurrence of phthalates in surface runoff, untreated and treated wastewater and fate during wastewater treatment. Chemosphere 78:1078-1084. doi:10.1016/j. chemosphere.2009.12.052

Daifullah AAM, Girgis BS, Gad HMH (2004) A study of the factors affecting the removal of humic acid by activated carbon prepared from biomass material. Colloid Surface A 235:1-10. doi:10.1016/j. colsurfa.2003.12.020

Davis A, Hunt W, Traver R, Clar M (2009) Bioretention technology: overview of current practice and future needs. J Environ Eng 135: 109-117. doi:10.1061/(ASCE)0733-9372(2009)135:3(109)

DEFRA (2008) 4-tert-Octylphenol: risk reduction strategy and analysis of advantages and drawbacks. Chemicals and Nanotechnologies Division, Department for Environment, Food and Rural Affairs, London, UK

Delle Site A (2001) Factors affecting sorption of organic compounds in natural sorbent/water systems and sorption coefficients for selected pollutants. J Phys Chem Ref Data 30:187-439. doi:10.1063/1.1347984

DiBlasi CJ, Li H, Davis AP, Ghosh U (2008) Removal and fate of polycyclic aromatic hydrocarbon pollutants in an urban stormwater bioretention facility. Environ Sci Technol 43:494-502. doi:10. $1021 / \mathrm{es} 802090 \mathrm{~g}$

Dierkes C, Geiger WF (1999) Pollution retention capabilities of roadside soils. Water Sci Technol 39:201-208. doi:10.1016/S0273-1223(99) 00024-4

Durjava MK, ter Laak TL, Hermens JLM, Struijs J (2007) Distribution of PAHs and PCBs to dissolved organic matter: high distribution coefficients with consequences for environmental fate modeling. Chemosphere 67:990-997. doi:10.1016/j.chemosphere.2006.10. 059

ECB (2002) Risk assessment report: 4-nonylphenol (branched) and nonylphenol. European Chemicals Bureau, Office for Official Publications of the European Communities, Luxembourg

ECB (2004) Risk assessment report: dibutyl phthalate (DBP). European Chemicals Bureau, Office for Official Publications of the European Communities, Luxembourg

ECB (2008) Risk assessment report: bis(2-ethylhexyl) phthalate (DEHP). European Chemicals Bureau, Office for Official Publications of the European Communities, Luxembourg
European Commission (2013) Building a green infrastructure for Europe. Publications Office of the European Union, Luxembourg. doi:10.2779/54125

Fassman E, Simcock R, Wang S (2013) Media specification for stormwater bioretention devices. Prepared by Auckland UniServices for Auckland Council, New Zealand ISBN 978-1927216-79-8 (Print), ISBN 978-1-927216-80-4 (PDF)

Gao Y, Ren L, Ling W, Gong S, Sun B, Zhang Y (2010) Desorption of phenanthrene and pyrene in soils by root exudates. Bioresour Technol 101:1159-1165. doi:10.1016/j.biortech.2009.09.062

Gong X (2013) Modification and utilization of sewage sludge-based activated carbon as metal adsorbents. Master thesis, University of British Columbia, Vancouver, Canada. Retrieved from http://hdl. handle.net/2429/44964

Greater Vancouver Sewerage \& Drainage District (2012) Infiltration rain garden. Metro Vancouver, Burnaby, BC http://www. metrovancouver.org/about/publications/Publications/ 05StormwaterSourceControlDesignGuidelinesRainGarden.pdf

Grebel JE, Mohanty SK, Torkelson AA, Boehm AB, Higgins CP, Maxwell RM, Nelson KL, Sedlak DL (2013) Engineered infiltration systems for urban stormwater reclamation. Environ Eng Sci 30:437454. doi:10.1089/ees.2012.0312

Hollender J, Koch B, Lutermann C, Dott W (2003) Efficiency of different methods and solvents for the extraction of polycyclic aromatic hydrocarbons from soils. Int J Environ Anal Chem 83:21-32. doi:10. 1080/0306731021000050723

Hong E, Seagren EA, Davis AP (2006) Sustainable oil and grease removal from synthetic stormwater runoff using bench-scale Bioretention studies. Water Environ Res 78:141-155. doi:10.2175/106143005X89607

International Organization for Standardization (2007) Soil qualityleaching procedures for subsequent chemical and ecotoxicological testing of soil and soil materials. Part 2: batch test using a liquid to solid ratio of 10 1/kg dry matter. ISO/TS $21268-2$

Jakob L, Hartnik T, Henriksen T, Elmquist M, Brändli RC, Hale SE, Cornelissen G (2012) PAH-sequestration capacity of granular and powder activated carbon amendments in soil, and their effects on earthworms and plants. Chemosphere 88:699-705. doi:10.1016/j. chemosphere.2012.03.080

Julinová M, Slavík R (2012) Removal of phthalates from aqueous solution by different adsorbents: a short review. J Environ Manag 94:13 24. doi:10.1016/j.jenvman.2011.09.006

Kalmykova Y, Rauch S, Strömvall A-M, Morrison G, Stolpe B, Hassellöv M (2010) Colloid-facilitated metal transport in peat filters. Water Environ Res 82:506-511. doi:10.2175/106143009x12529484815430

Kalmykova Y, Björklund K, Strömvall A-M, Blom L (2013) Partitioning of polycyclic aromatic hydrocarbons, alkylphenols, bisphenol A and phthalates in landfill leachates and stormwater. Water Res 47:13171328. doi:10.1016/j.watres.2012.11.054

Kalmykova Y, Moona N, Strömvall A-M, Björklund K (2014) Sorption and degradation of petroleum hydrocarbons, polycyclic aromatic hydrocarbons, alkylphenols, bisphenol a and phthalates in landfill leachate using sand, activated carbon and peat filters. Water Res 56: 246-257. doi:10.1016/j.watres.2014.03.011

Kilduff JE, Karanfil T, Weber WJ (1996) Competitive interactions among components of humic acids in granular activated carbon adsorption systems: effects of solution chemistry. Environ Sci Technol 30: 1344-1351. doi:10.1021/es950546z

van de Kreeke J, de la Calle B, Held A, Bercaru O, Ricci M, Shegunova P, Taylor P (2010) IMEP-23: the eight EU-WFD priority PAHs in water in the presence of humic acid. Trend Anal Chem 29:928937. doi:10.1016/j.trac.2010.04.009

KWL (2012) Rain gardens: design, implementation, and maintenance considerations. Kerr Wood Leidal Consulting Engineers, Burnaby, BC, Canada http://www.kwl.ca/sites/ default/files/RainGardens-paper-OCR.pdf 
Kyoichi K (1987) Chemistry of soil organic matter. In: Developments in soil science, vol 17. Elsevier. doi:10.1016/S0166-2481(08)70074-6

LeFevre GH, Novak PJ, Hozalski RM (2012a) Fate of naphthalene in laboratory-scale bioretention cells: implications for sustainable stormwater management. Environ Sci Technol 46:995-1002. doi: $10.1021 / \mathrm{es} 202266 \mathrm{z}$

LeFevre GH, Hozalski RM, Novak PJ (2012b) The role of biodegradation in limiting the accumulation of petroleum hydrocarbons in raingarden soils. Water Res 46:6753-6762. doi:10.1016/j.watres.2011.12.040

LeFevre GH, Hozalski RM, Novak PJ (2013) Root exudate enhanced contaminant desorption: an abiotic contribution to the rhizosphere effect. Environ Sci Technol 47:11545-11553. doi:10.1021/es402446v

LeFevre G, Paus K, Natarajan P, Gulliver J, Novak P, Hozalski R (2014) Review of dissolved pollutants in urban storm water and their removal and fate in bioretention cells. J Environ Eng. doi:10.1061/ (ASCE)EE.1943-7870.0000876

Li B (2011) Perfluorinated compounds in landfill leachate and their effect on the performance of sodium bentonite landfill liners. Master thesis, University of British Columbia, Vancouver, Canada. http:// circle.ubc.ca/handle/2429/37095

Li Q, Snoeyink VL, Mariñas BJ, Campos C (2003) Pore blockage effect of NOM on atrazine adsorption kinetics of PAC: the roles of PAC pore size distribution and NOM molecular weight. Water Res 37: 4863-4872. doi:10.1016/j.watres.2003.08.018

Mackay D, Shiu WY, Ma K-C, Lee SC (2006) Handbook of physicalchemical properties and environmental fate for organic chemicals. CRC Press, Taylor \& Francis Group, Boca Raton. isbn: 9781566706872

Morrison GMP, Revitt DM, Ellis JB (1990) Metal speciation in separate stormwater systems. Water Sci Technol 22:53-60

Mullane JM, Flury M, Iqbal H, Freeze PM, Hinman C, Cogger CG, Shi Z (2015) Intermittent rainstorms cause pulses of nitrogen, phosphorus, and copper in leachate from compost in bioretention systems. Sci Total Environ 537:294-303. doi:10.1016/j.scitotenv.2015.07.157

Murakami M et al (2008) Multiple evaluations of the removal of pollutants in road runoff by soil infiltration. Water Res 42:2745-2755. doi: 10.1016/j.watres.2008.02.004

Muthanna TM, Viklander M, Blecken G, Thorolfsson ST (2007) Snowmelt pollutant removal in bioretention areas. Water Res 41: 4061-4072. doi:10.1016/j.watres.2007.05.040

Newcombe G, Morrison J, Hepplewhite C, Knappe DRU (2002) Simultaneous adsorption of MIB and NOM onto activated carbon: II. Competitive effects. Carbon 40:2147-2156. doi:10.1016/S00086223(02)00098-2

O'Neill S, Davis A (2012) Water treatment residual as a Bioretention amendment for phosphorus. I: Evaluation Studies J Environ Eng 138:318-327. doi:10.1061/(ASCE)EE.1943-7870.0000409

OECD (2000) Test no. 106: adsorption-desorption using a batch equilibrium method. OECD guidelines for the testing of chemicals, section 1: physical-chemical properties. OECD Publishing, Paris. doi:10. 1787/9789264069602-en

Pelekani C, Snoeyink VL (1999) Competitive adsorption in natural water: role of activated carbon pore size. Water Res 33:1209-1219. doi:10. 1016/S0043-1354(98)00329-7

Quinlivan PA, Li L, Knappe DRU (2005) Effects of activated carbon characteristics on the simultaneous adsorption of aqueous organic micropollutants and natural organic matter. Water Res 39:16631673. doi:10.1016/j.watres.2005.01.029
Rouhi A, Schwartz D (2007) Physical assessment of selected rain gardens in Fairfax County, Virginia. The Northern Virginia Soil and Water Conservation District, Fairfax, Virginia http://www.fairfaxcounty. gov/nvswcd/raingardenstudy.pdf

Smith KM, Fowler GD, Pullket S, Graham NJD (2009) Sewage sludgebased adsorbents: a review of their production, properties and use in water treatment applications. Water Res 43:2569-2594. doi:10. 1016/j.watres.2009.02.038

Song YF, Jing X, Fleischmann S, Wilke B-M (2002) Comparative study of extraction methods for the determination of PAHs from contaminated soils and sediments. Chemosphere 48:993-1001. doi:10. 1016/S0045-6535(02)00180-7

StormTac database: Standard stormwater concentrations, v. 2016-08 (2016) http://www.stormtac.com/. Accessed 2016-11-22

Strömvall A-M, Norin M, Pettersson TJR (2006) Organic contaminants in urban sediments and vertical leaching of in road ditches. In: Morrison GM, Rauch S (eds) Proceedings of the 8th Highway and Urban Environment Symposium, Nicosia, Cyprus, 12-14 June 2006, pp 235-247

Tegelberg L, Svensson G (2013) Utvärdering av Svenskt Vattens rekommenderade sammanvägda avrinningskoefficienter (Assessment of Svenskt Vatten's recommended runoff coefficients). Report 2013-05, Svenskt Vatten Utveckling (in Swedish)

Tian J, Yi S, Imhoff PT, Chiu P, Guo M, Maresca JA, Beneski V, Cooksey SH (2014) Biochar-amended media for enhanced nutrient removal in stormwater facilities. In: Paper presented at the world environmental and water congress: water without borders. ASCE, Portland, OR. doi:10.1061/9780784413548

Trowsdale SA, Simcock R (2011) Urban stormwater treatment using bioretention. J Hydrol 397:167-174. doi:10.1016/j.jhydrol.2010.11.023

Ulrich BA, Im EA, Werner D, Higgins CP (2015) Biochar and activated carbon for enhanced trace organic contaminant retention in stormwater infiltration systems. Environ Sci Technol 49:62226230. doi: $10.1021 /$ acs.est.5b00376

US EPA (2012) EPI Suite ${ }^{\mathrm{TM}}$-Estimation Program Interface (v. 41). Downloaded from https://www.epa.gov/tsca-screening-tools/episuitetm-estimation-program-interface on 2016-08-26

US EPA (2014) Green infrastructure. http://water.epa.gov/infrastructure/ greeninfrastructure/index.cfm. Accessed 2016-11-18

Wang F, Ji R, Jiang Z, Chen W (2014) Species-dependent effects of biochar amendment on bioaccumulation of atrazine in earthworms. Environ Pollut 186:241-247. doi:10.1016/j.envpol.2013.12.012

Waterbucket (2014) Green infrastructure. http://waterbucket.ca/gi/. Accessed 2016-11-18

Wen ZD, Gao DW, Li Z, Ren NQ (2013) Effects of humic acid on phthalate adsorption to vermiculite. Chem Eng J 223:298-303. doi:10.1016/j.cej.2013.03.012

Zgheib S, Moilleron R, Saad M, Chebbo G (2011) Partition of pollution between dissolved and particulate phases: what about emerging substances in urban stormwater catchments? Water Res 45:913-925. doi:10.1016/j.watres.2010.09.032

Zhang W, Brown GO, Storm DE, Zhang H (2008) Fly-ash-amended sand as filter media in bioretention cells to improve phosphorus removal water. Environ Res 80:507-516. doi:10.2175/106143008X266823

Zhang K, Randelovic A, Page D, McCarthy DT, Deletic A (2014) The validation of stormwater biofilters for micropollutant removal using in situ challenge tests. Ecol Eng 67:1-10. doi: 10.1016/j.ecoleng.2014.03.004 